\title{
Rancang Bangun Aplikasi Mobile Learning Client Server Berbasis Moodle Pada Platform Android Untuk Materi Training Tenaga Pemasaran Di Miracle Agency Cabang Bangka
}

\author{
Ode Riski \\ Program Studi Teknik Informatika \\ STMIK Atma Luhur \\ Jln. Jend. Sudirman - Selindung Pangkalpinang \\ Bangka Belitung \\ ode.r@yahoo.com
}

\author{
Delpiah Wahyuningsih \\ Program Studi Teknik Informatika \\ STMIK Atma Luhur \\ Jln. Jend. Sudirman - Selindung Pangkalpinang \\ Bangka Belitung \\ delphibabel@atmaluhur.ac.id
}

\begin{abstract}
Abstrak- Miracle Agency cabang Bangka merupakan Kantor Pemasaran Mandiri (KPM) dari PT. Prudential Life Assurance yang bergerak dalam bidang asuransi yang berada di Jl. Alexander blok $9 \& 10$ A commercial area citraland dan memliki lebih dari 300 tenaga pemasaran. Sistem training yang digunakan oleh Miracle Agency cabang Bangka untuk tenaga pemasaran adalah dengan pembelajaran secara konvensional, maka antara pengajar dan peserta melakukan pertemuan secara langsung yang berada pada ruang fisik yang sama. M-Learning adalah metode pembelajaran dengan menggunakan teknologi informasi yang dapat membantu peserta training dalam mempelajari materi training tanpa harus mengikuti pertemuan secara langsung. Aplikasi mobile learning client server berbasis moodle pada platform android adalah suatu solusi untuk menyelesaikan berbagai permasalahan pada Miracle Agency yang merupakan Kantor Pemasaran Mandiri (KPM) dari PT. Prudential Life Assurance karena dengan mobile learning dan smart phone sebagai media penghubung, peserta training atau tenaga pemasaran dapat dengan mudah mengakses topik materi tanpa harus mengikuti training sebelumnya. Dapat disimpulkan dengan menggunakan aplikasi mobile learning ini sistem pembelajaran akan dapat dilakukan secara mudah,efisien dan tentunya dengan cakupan waktu yang lebih luas.
\end{abstract}

Kata Kunci- Android, Mobile Learning, Client Server, Moodle, Miracle Agency

\section{Pendahuluan}

Meningkatnya perkembangan perangkat komunikasi telepon selular belakangan ini mengalami pertumbuhan yang sangat pesat yang didukung dengan disertakannya teknologi terbaru dalam perangkat tersebut. Perkembangan ini juga ditambah dengan konvergensi perangkat komunikasi yang mampu menangani proses voice, data dan video dalam satu perangkat.

Mobile learning adalah pembelajaran yang unik karena pembelajar dapat mengakses materi, arahan dan aplikasi yang berkaitan dengan pembelajaran kapan-pun dan dimana-pun. Hal ini akan meningkatkan perhatian pada materi pembelajaran, membuat pembelajaran menjadi pervasif, dan dapat mendorong motivasi pembelajar kepada pembelajaran sepanjang hayat (lifelong learning).

Miracle Agency cabang Bangka merupakan Kantor Pemasaran Mandiri (KPM) dari PT. Prudential Life Assurance yang bergerak dalam bidang asuransi yang berada di Jl. Alexander blok $9 \& 10$ A commercial area citraland dan memliki lebih dari 300 tenaga pemasaran. Sistem training yang digunakan oleh Miracle Agency cabang Bangka untuk tenaga pemasaran adalah dengan pembelajaran secara konvensional, maka antara pengajar dan peserta melakukan pertemuan secara langsung yang berada pada ruang fisik yang sama.

\section{Metode Penelitian}

Metode penelitian ini menggunakan metode waterfall. Metode waterfall adalah sebuah metode dalam pengembangan sistem yang dilakukan untuk membuat pembaruan sistem yang berjalan. Menurut Buku Rosa Metode pengembangan sistem merupakan proses mengembangkan atau mengubah suatu sistem perangkat lunak dengan menggunakan metode-metode atau model-model yang digunakan orang untuk mengembangkan sitem-sistem perangkat lunak sebelumnya dengan memiliki alur hidup perangkat lunak secara sekuensial atau terurut dimulai dari analisis, desain, pengodean, pengujian, dan tahap pendukung (support). Dan untuk gambarannya dapat di ilustrasikan seperti gambar berikut ini :

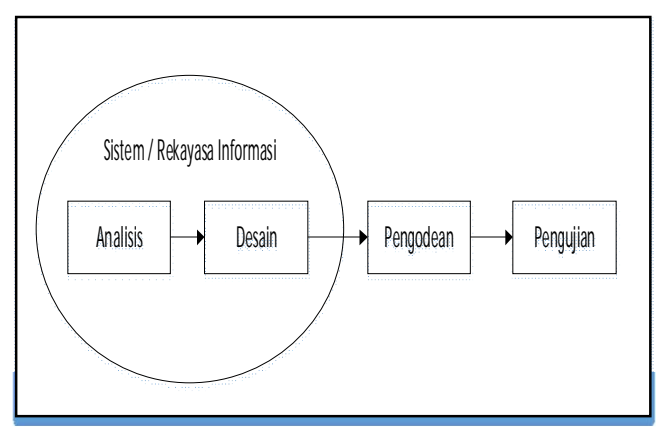

Gambar 1. Tahapan penelitian dengan metode Waterfall 
Dalam pengembangan sistem seperti gambar ilustrasi diatas dapat dijabarkan seperti berikut :

\section{1) Analisis}

Analisis atau analisa ini merupakan tahap awal yang dilakukan oleh peneliti dalam mengembangkan sistem. Dalam analisis ini harus mendapatkan beberapa hal yang dianggap menunjang penelitian yang dilakukan, seperti : mencari permasalahan yang ada, mengumpulkan data (data fisik, non fisik), wawancara dan lain-lain. Dalam tahap awal ini penulis dituntut untuk benar-benar melakukan penelitian yang terarah seperti dalam penelitian ini. Untuk menentukan pokok permasalahan peneliti harus memilih terlebih dahulu permasalahan globalnya (yaitu : pada kantor pemasaran mandiri Miracle Agency Cabang Bangka), kemudian membagi lagi menjadi beberapa sub kecil (yaitul : sistem pembelajaran training), dan membagi kembali hingga tertuju pada titik fokus (misal : aplikasi mobile learning).

\section{2) Desain}

Desain yang dimaksud bukan hanya tampilan atau interfacenya saja, tetapi yang dimaksud desain dalam metode ini adalah desain sistem yang meliputi : alur kerja sistem, cara pengoprasian sistem, hasil keluaran (output) dengan menggunakan metode-metode seperti UML (Unified Modeling Language) tampilan sistem dan lain-lain yang telah disesuaikan dengan analisis kebutuhan pada tahap awal untuk menyelesaikan permasalahan tersebut.

\section{3) Pengkodean}

Programmer memasukan script kode pemrograman kedalam sebuah software programming untuk menghasilkan aplikasi yang telah di desain, software programming yang dapat digunakan harus disesuaikan dengan desain sistem.

4) Pengujian dan tahap pendukung (support)

Tahap ini adalah tahap pengujian dan tahap pendukung yang artinya sistem yang telah dibuat dari hasil analisis masalah yang telah melalui tahap-tahap desain, pengodean barulah masuk kedalam pengujian sistem, sehingga akan dapat diketahui seperti apa hasil kinerja sistem yang baru ini dibandingkan dengan sistem yang lama, kemudian dapat diketahui pula apakan dalam sistem yang baru ini masih ada kelemahan yang kemudian akan dikembangkan oleh peneliti berikutnya. Dalam penelitian ini dilakukan implementasi aplikasi pada perangkat smartphone android untuk dijuji coba menggunakan metode black box dan melakukan evaluasi jika terjadi kesalahan terhadap jalannya aplikasi.

\section{PEMBAhASAN}

\section{A. Analisis Sistem Berjalan}

Proses pembelajaran training konvensional di Miracle Agency Bangka ini dilakukan dengan beberapa tahap, yaitu :
- Pengajar dan tenaga pemasaran bertemu secara langsung di dalam suatu ruangan training.

- Pengajar membuat dan menyampaikan materi secara langsung kepada para tenaga pemasaran.

- Tenaga pemasaran mempelajari materi yang telah disampaikan pengajar.

- Apabila tenaga pemasaran ada pertanyaan atau ada yang belum mengerti mengenai materi, para tenaga pemasaran dapat mananyakan secara langsung kepada pengajar.

- Pengajar menjawab pertanyaan yang ditanyakan oleh tenaga pemasaran.

- Pengajar memberikan tugas kepada para tenaga pemasaran.

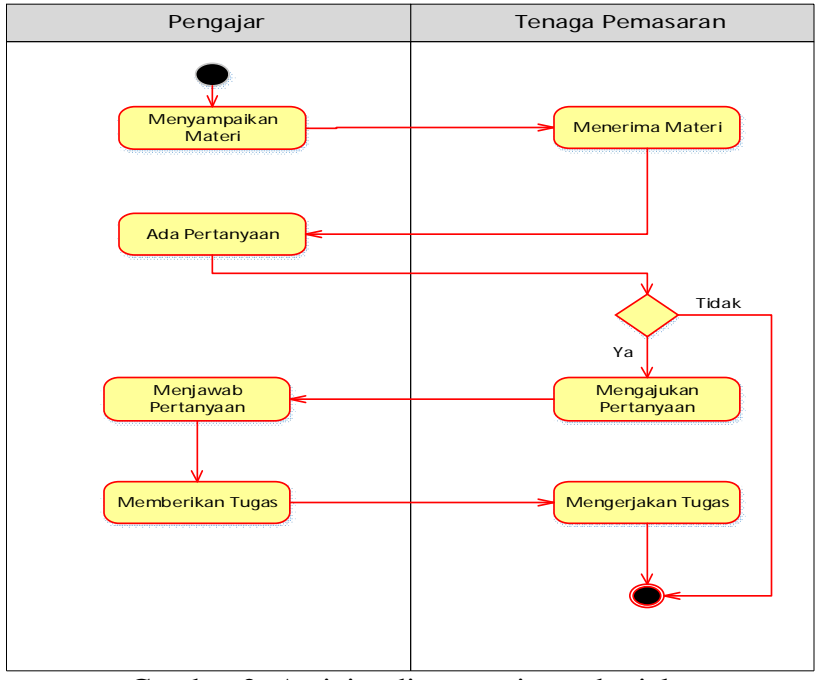

Gambar 2. Activity diagram sistem berjalan

\section{B. Analisa Sistem Usulan}

Berdasarkan hasil dari penelitian yang berjalan, sistem yang diusulkan untuk memerikan solusi pada permasalahan ini adalah dengan membuat Aplikasi Mobile Learning Client Server Berbasis Moodle Pada Platform Android Untuk Materi Training Tenaga Pemasaran Di Miracle Agency Cabang Bangka. Dalam sistem ini, tenaga pemasaran diberikan kemudahan dalam mendapatan materi dan tugas yang diberikan pengajar sehingga tenaga pemasaran dapat mempelajari di manapun . Berikut gambar rancangan solusi yang ditawarkan dalam perancangan sistem ini : 


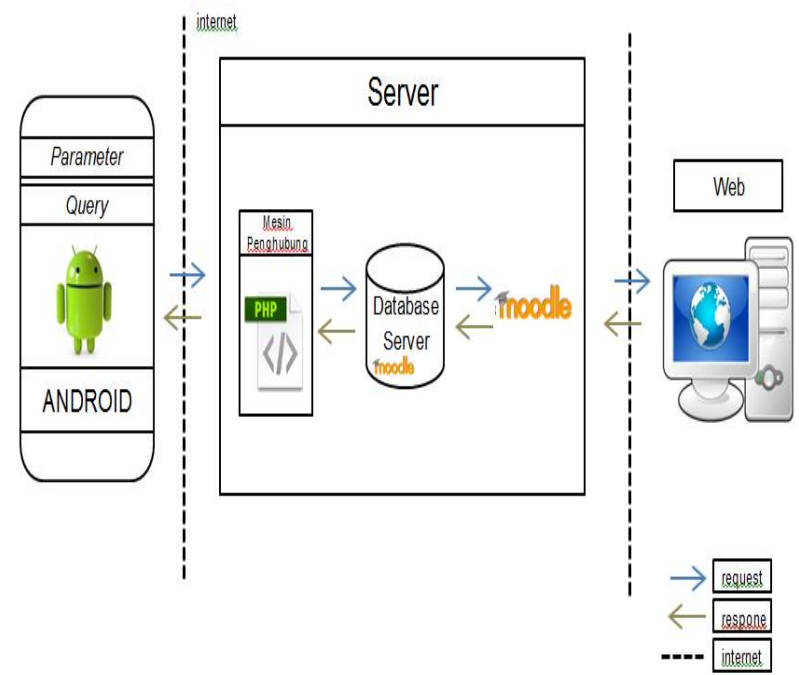

Gambar 3. Solusi Yang Ditawarkan

\section{Deskripsi Kebutuhan Sistem}

Untuk membangun sebuah sistem yang efisien, kebutuhan sistem merupakan hal yang harus diperhatikan. Mengetahui kebutuhan sistem akan membantu dalam pembangunan sistem.

\section{1) Sistem Yang Akan Dibangun}

Untuk kebutuhan sistem yang akan dibangun tedapat dua bagian yakni dari

kebutuhan sistem dari perangkat Android dan mesin penghubung menggunakan bahasa pemrograman PHP sebagai penghubung antara sistem di perangkat Android dengan dabatase server. Dari sisi server, sistemnya telah terbentuk sendiri ketika memasang Moodle di server, sehingga bagian sisi server tidak dibahas dalam analisa sistem yang akan dibangun.

\section{Fungsi Sistem}

Secara umum fungsi sistem ada dua bagian yaitu sistem yang akan dibangun dari sisi perangkat Android dan mesin penghubung.

\section{1) Fungsi Sistem Dari Sisi Perangkat Android}

Sistem yang akan dibangun dari sisi perangakat Android memiliki fungsi-fungsi sebagai berikut:

- Fungsi login ke sistem di perangkat Android.

- Menampilkan course berserta isinya.

- Menampilkan tugas berdasarkan course berserta isinya.

- Menampilkan nilai berdasakan tugas yang diberikan di setiap course.

- Kirim dan update tugas berupa teks.

- Download file berdasarkan course yang ada.

\section{2) Fungsi Mesin Penghubung}

Mesin Penghubung yang akan dibangun memiliki fungsi-fungsi sebagai berikut :

- Fungsi untuk login.

- Fungsi untuk memilih course yang akan ditampilkan.

- Fungsi memilih tugas yang akan ditampilkan.

- Fungsi kirim tugas yang akan dikirim dari perangkat Android.

- Fungsi memilih file untuk di download.

\section{E. Deskripsi Pengguna}

Pengguna dari sistem ini adalah tenaga pemasaran dan pengajar. Tapi secara umum pengguna utamanya tenaga pemasaran, tenaga pemasaran hanya bisa mengakses isi dari konten mobile learning sesuai yang meraka enrol dan melalukan input berupa teks.

\section{F. Perancangan Sistem}

Setelah dilakukan beberapa tahapan dalam analisa sistem, maka dapat dilakukan beberapa perancangan sistem mobile learning client server berbasis Android. Perancanganperancangan yang akan dijelaskan dalam laporan ini meliputi perancangan model dalam bentuk UML (Unified Modeling Language) yang terdiri dari Use Case Diagram, Class Diagram, Activity Diagram, Sequence Diagram dan Deployment Diagram.

\section{G. Hubungan Class di Android Dengan Mesin Penghubung}

Seperti yang telah dijelaskan pada bagian analisa, untuk mengakses konten learning yang ada di server, sistem yang berjalan di Android membutuhkan bantuan dari luar, yaitu sebuah mesin penghubung. Mesin penghubung berfungsi sebagai jembatan antara sistem di Android dengan server. Jadi, mesin penghubung ini berperan sebagai perantara request dari sistem di Android untuk diteruskan ke server dan perantara respon dari server untuk diteruskan ke sistem di Android. Untuk lebih jelasnya bagaimana sistem kerja dari mesin penghubung ini dapat dilihat pada gambar 4 dibawah ini.

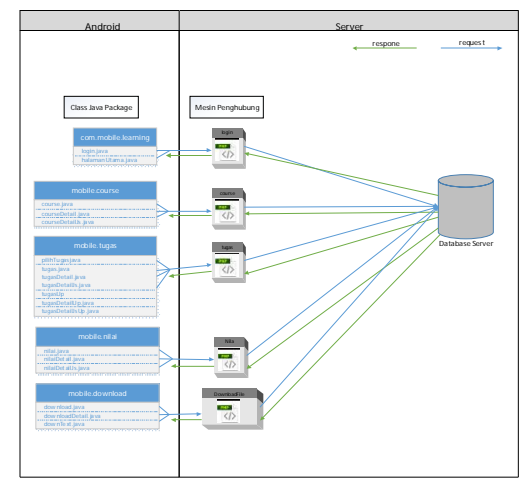

Gambar 4. Hubungan Class di Android dengan mesin Penghubung 


\section{H. Hubungan Struktur Menu Sistem}

Berikut struktur menu dari sistem yang akan dibangun dapat dilihat pada gambar 5. di bawah ini:

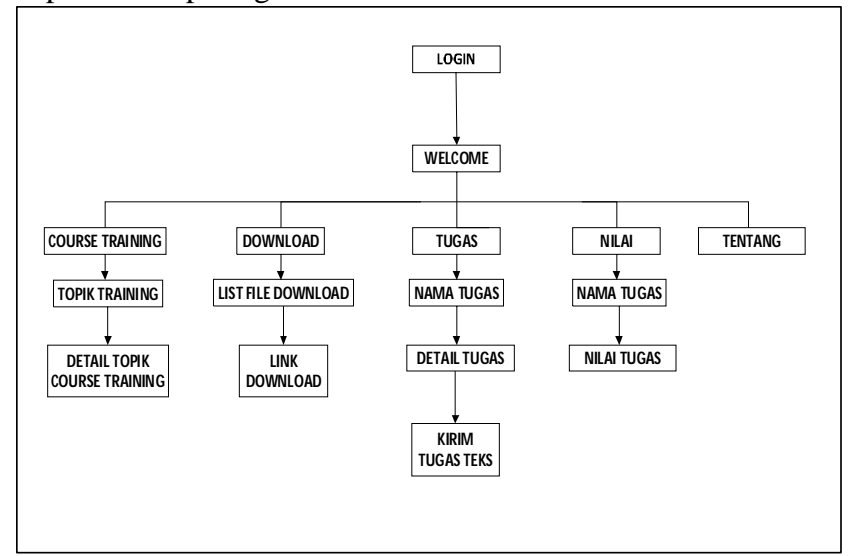

Gambar 5. Rancangan Struktur Menu

\section{IMPLEMENTASI}

\section{A. Tahap Implementasi}

Pada tahap-tahap implementasi ini akan dijelaskan bagaimana tahapan yang penulis lakukan dalam implementasi aplikasi yang telah dibangun. Adapun tahap-tahap yang dilakukan adalah:

\section{1) Instalasi Moodle}

Tahap instalasi Moodle merupakan tahap pemasangan Moodle di server yang nantinya sebagai server konten mobile learning. Moodle yang digunakan pada tahap instalasi ini adalah versi moodle 1.9. Pemilihan versi Moodle 1. Ini dikarenakan kestabilannya. Untuk melakukan instalasi moodle ada beberapa tahapan yang harus kita lakukan :

- Ekstrak file Moodle yang telah didownlaad dari situs Moodle.

- Letakkan file moodle di dalam flder oublic_html pada server.

- Akses melalui browser, kemudian lakukan instalasi sesuai intruksi.

\section{2) Konfigurasi Awal}

Tahap konfigurasi awal ini adalah tahap konfigurasi beberapa file di server, diantaranya:

a) Data directory Moodle

Secara default saat install Moodle di Server, maka data directory akan otomatis terbuat di folder htdocs. Selanjutnya kita implentasikan file moodle ke hosting ke dalam directory public_html pada server hostinger. Untuk lebih jelasnya dapat dilihat pada gambar $4.26 \mathrm{di}$ bawah ini.

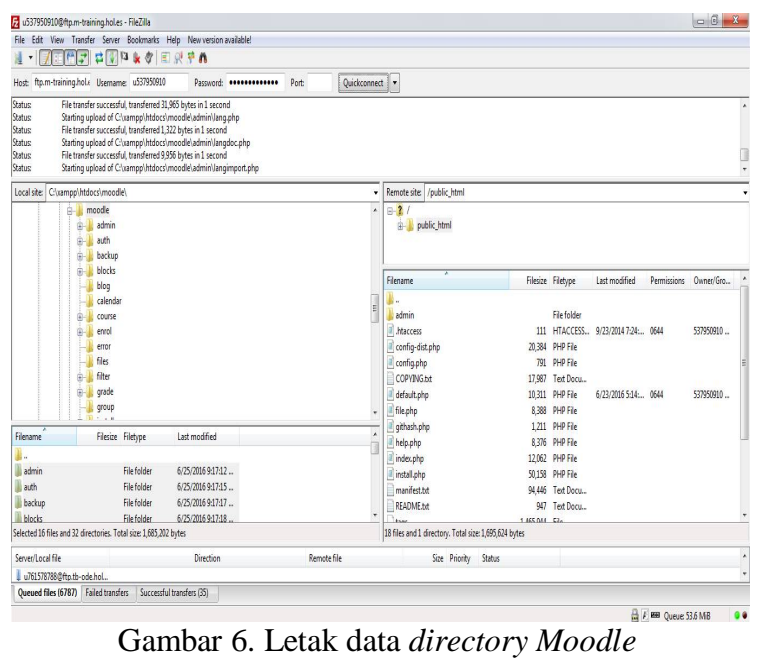

\section{b) File .htaccess}

Agar salah satu menu di aplikasi mobile learning nantinya bisa berjalan sesuai yang diharapkan. Maka, diperlukan konfigurasi pada file .htaccess Moodle. File ini terletak di dalam data directory moodle, tepatnya dalam directory moodledata. Hasil akhir konfigurasi file .htaccess dapat dilihat pada gambar 4.27 di bawah ini.

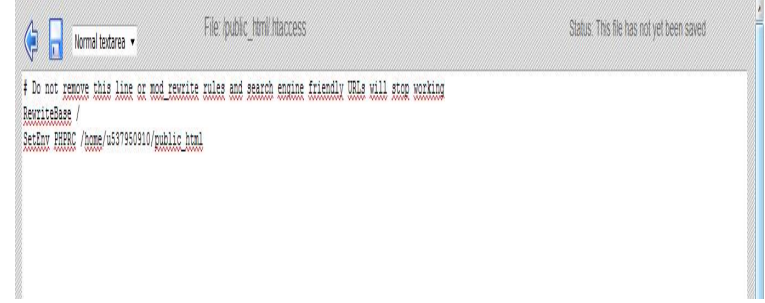

Gambar 7. Konfigurasi file .htaccess

\section{c) File config.php}

Konfigurasi file config.php pada folder moodle ini bertujuan sebagai penghubung moodle agar dapat terkoneksi dengan hosting.

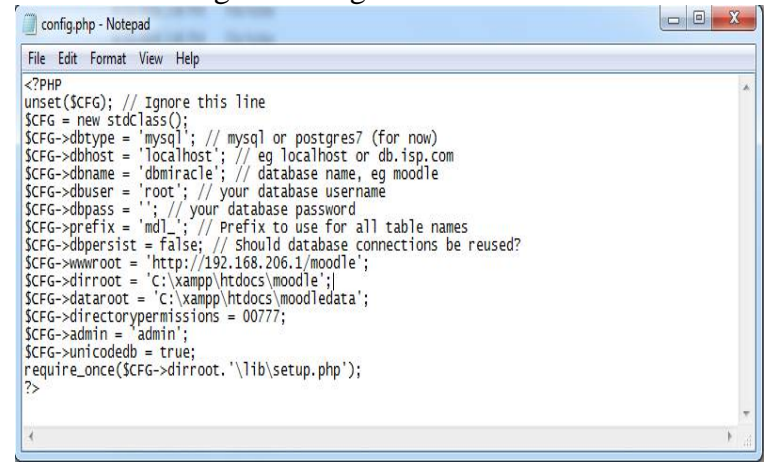

Gambar 8. Pengaturan File config.php web server localhost 


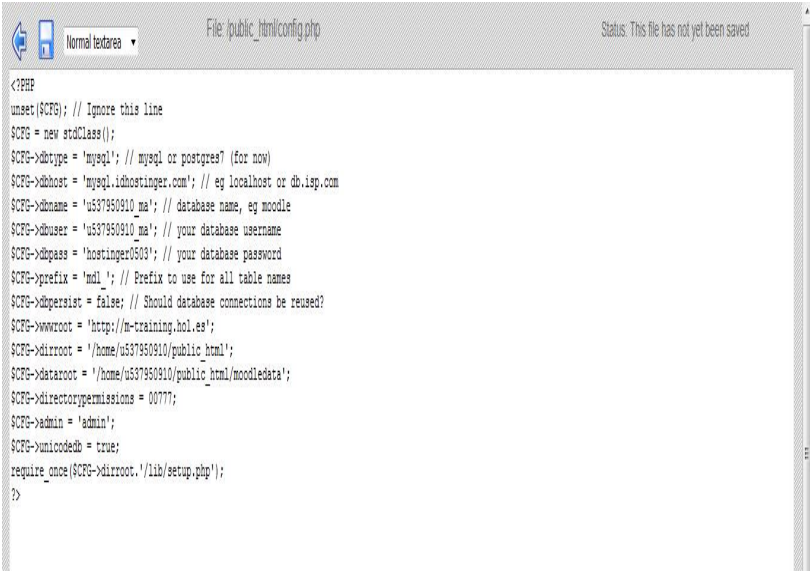

Gambar 9. Pengaturan File config.php pada web server hosting

\section{3) Instalasi Mesin Penghubung ke Hosting}

Seperti yang telah dijelaskan pada bab analisa dan perancangan, mesin penghubung mempunyai peran penting dalam aplikasi mobile learning client server berbasis Android ini. Mesin ini berperan sebagai penghubung antara aplikasi di Android dengan konten learning yang ada di server, sehingga untuk bisa implementasi aplikasi yang telah dibuat, kita harus meletakan Mesin ini bersamaan dengan file Moodle di localhost ataupun hosting. File mesin ini diletakan di dalam sebuah direktory yang di beri nama directory "mobile". Untuk lebih jelasnya dapat dilihat pada gambar 10 dibawah:
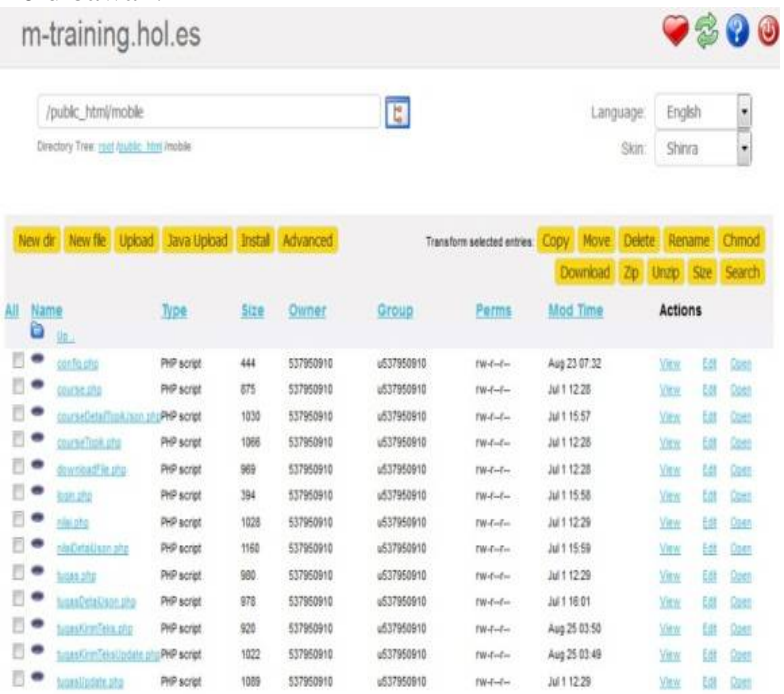

Gambar 10. Letak directory mesin penghubung web server hosting

\section{4) Instalasi Aplikasi Mobile Learning}

Dalam tahap ini merupakan tahap instalasi aplikasi mobile learning yang telah dibangun berdasarkan analisa dan perancangan. Aplikasi dipasang pada perangkat
Android. Perangkat Android yang digunakan yaitu smartphone Android. Untuk melakukan instalasi aplikasi, cukup klik aplikasi mobile learning yang telah di pakcage ke dalam format *.apk (Miracle Learning.apk) pada perangkat Android dan selesai. Aplikasi siap dijalankan.

5) Implementasi Kerja Aplikasi

a) Halaman Login

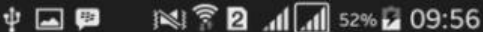
Miracle Learning

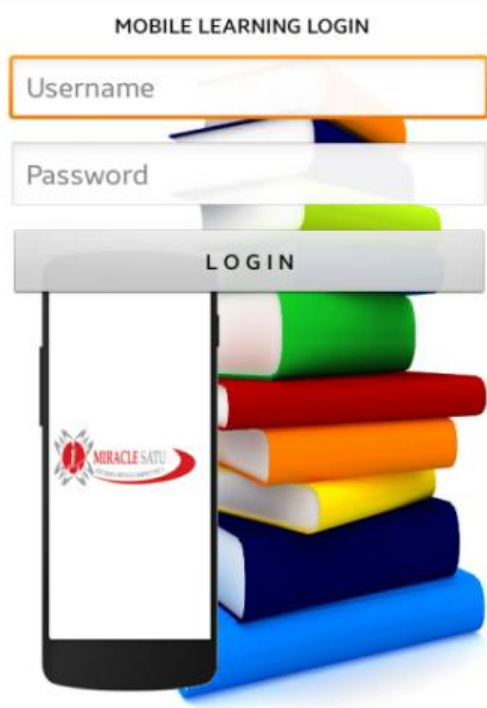

Gambar 11. Halaman Login

b) Halaman Menu Utama

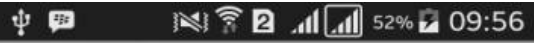

Miracle Learning

Selamat datang admin
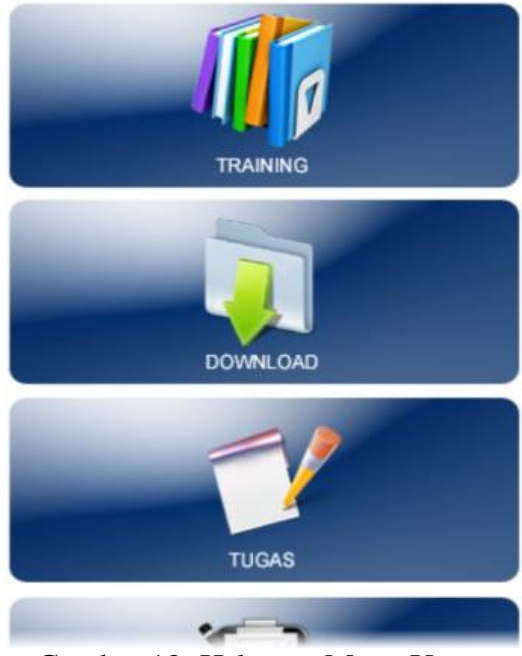

Gambar 12. Halaman Menu Utama 
c) Halaman Course Training

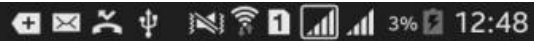

MIRACLE AGENCY

COURSE TRAINING YANG DI AMBIL

ittp://m-trainingtholes/

Finance Planning

Sales idea

Agency Training Module

Fast Start 2016

MT 4

New Bussines Opportunity

Gambar 13. Halaman Course Training

d) Halaman Topik Course Training

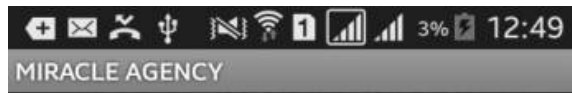

TOPIK COURSE TRAINING

Silahkan Pllih Topik yang Ada

http://m-training holkes/

Finance Planning Rev Ar

Gambar 14. Halaman Topik Course Training

e) Halaman Isi Topik Course Training $\triangle$ Menyimpan screenshot..

MIRACLE AGENCY

Finance Planning Rev Ar

Financial Plaining adalah suatu startegi dalam mengatur pendapatan yang diperoleh agar dapat mencukupi seluruh kebutuhan hidup. Tujuannya adalah untuk mengendalikan saati ini \& masa depan, beserta resiko-resiko ynag ada dalam kehidupan.

Metode penjualan

Selama ini kita mengenal 2 metode penjualan 1.Push selling (product based selling)

Menjual produk karena keunggulan produk tersebut.

2.Needs based selling

Menjual produk sesuai dengan kebutuhan pembeli.

Mengapa metode "Need base selling" lebih baik ? -Nasabah lebih mengerti dengan produk yang dibeli

-Nasabah membeli produk karena merasa "butuh" bukan karena "terpaksa", sehingga kemungkinan lapsed menjadi sangat kecil

-Manghadapi market yang lebih "berpendidikan"

-Meningkatkan rasio closing dan kualitas closing -Memberikan "nilai tambah" seorang agen dalam menghadapi persaingan

Gambar 15. Halaman Isi Topik Course Training

\section{f) Halaman Download File Course Training}

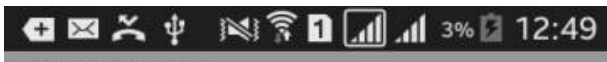
MIRACLE AGENCY

File sesuai materi training yang telah anda ambil

http://192.168206.10/modedletata/16/Materi/

FP Rev AR DPpix

Gambar 16. Halaman Download File Course Training

g) Halaman Tugas / Rencana Kerja 


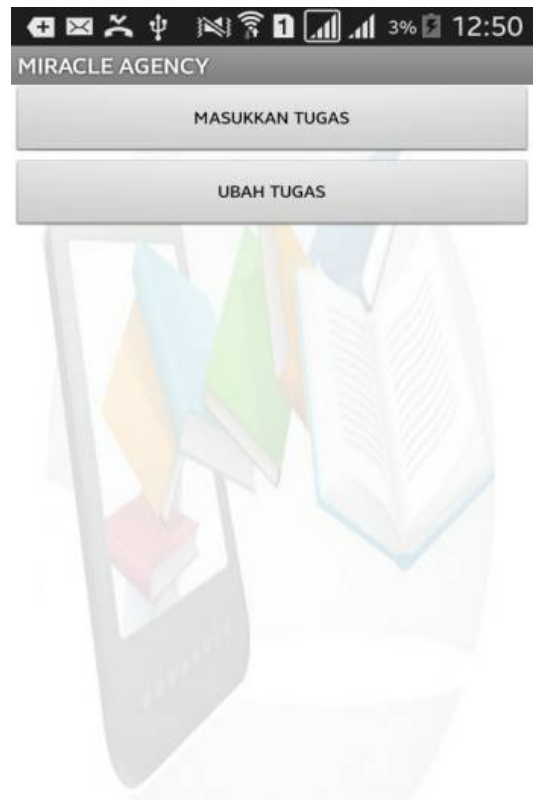

Gambar 17. Halaman Tugas/Rencana Kerja

\section{h) Halaman Nilai Tugas / Rencana Kerja}

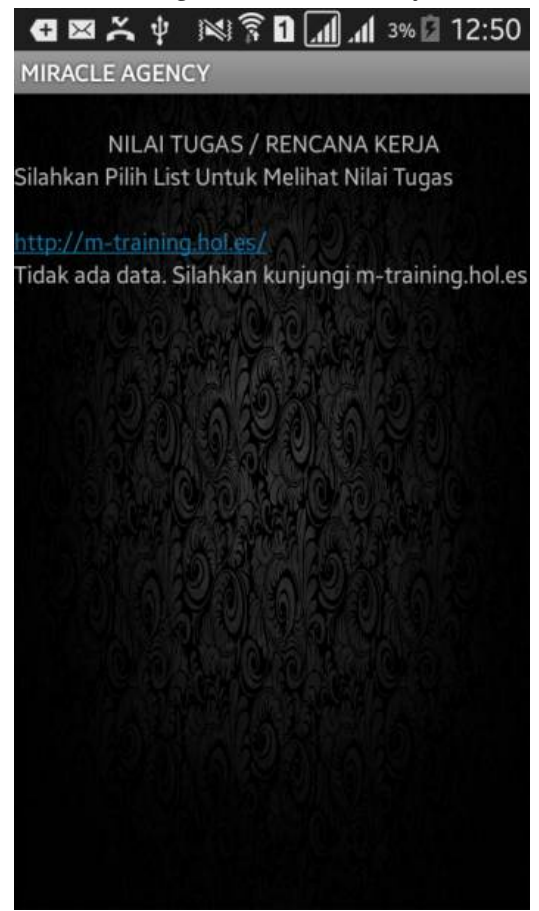

Gambar 18. Halaman Nilai Tugas / Rencana Kerja

\section{B. Pengujian}

Tahapan pengujian dilakukan untuk mengetahui apakah sistem yang dibangun telah sesuai dengan yang di harapakan.
Pada tahap pengujian sistem ini perangkat keras yang digunakan yaitu smartphone Android.

\section{1) Pengujian Akses Aplikasi Mobile Learning}

Pengujian yang dilakukan bertujuan untuk mengetahui proses hasil dari sistem, yaitu memperlihatkan aplikasi mobile learning yang telah dibangun bias diakses melalui perangkat Android. Hasil dari pengujian dapat dilihat ketika telah melakukan login ke sistem dan sistem menampilkan menu dan submenu. Kemudian pembuktian dilakukan untuk membuktikan bahwa konten yang ditampilkan di sistem sesuai dengan database server. Untuk alamat alamat website yang digunakan sebagai server mobile learning untuk Android adalah http://mtraining.hol.es.

\section{2) Pengujian Blackbox APliaksi Mobile Learning}

Pengujian sistem dilakukan untuk memeriksa kekompakan atau kinerja antar komponen sistem yang diimplementasikan. Tujuan utama dari pengujian sistem adalah untuk memastikan bahwa elemen-elemen atau komponenkomponen dari sistem telah berfungsi sesuai dengan yang diharapkan. Salah satu metode pengujian jenis ini dikenal dengan pengujian blackbox.

\section{Kesimpulan}

Berdasarkan uraian dan hasil analisa yang telah dilakukan selama pengerjaan Aplikasi Mobile Learning Client Server Berbasis Moodle Pada Platform Android Untuk Materi Training Tenaga Pemasaran Di Miracle Agency Cabang Bangka ini, maka dapat diambil kesimpulan sebagai berikut:

- Aplikasi Mobile Learning yang dibuat ini juga dapat mempermudah para tenaga pemasaran untuk mempelajari kembali materi training di Kantor Miracle Agency Cabang Bangka melalui perangkat Android.

- Secara umum aplikasi yang dibangun telah bisa berjalan pada perangkat Android dan bisa mengakses konten yang ada di server Moodle melalui mesin penghubung. Selain itu, aplikasi yang berjalan di Android telah bisa memanipulasi database moodle dalam bentuk aksi update.

- Berdasarkan hasil pengujian yang dilakukan pada kondisi tertentu, sistem di Android tidak bisa mengakses server dikarenakan adanya gangguan teknis diluar sistem seperti, gangguan jaringan, server lambat dalam respon, atau padatnya jaringan, bukan karena sistem di Android error.

- Adanya kekurangan aplikasi ini masih belum bisa untuk melakukann enrol course secara langsung dari perangkat Android, belum lengkapnya fitur yang tersedia, dan aspek keamanan dari sisi client. 


\section{DAFTAR PUSTAKA}

[1] Amiral, Muhammad. Aplikasi Pengingat Sholat dan Arah Kiblat Menggunakan Global Positioning System (GPS) berbasis Android 1.6. Teknik Informatika, Institut Teknologi Indonesia. 2010

[2] Dharwiyanti, S., dan Wahono, R.S. Pengantar Unified Modeling Language (UML). Ilmu Komputer, 2003, 1-13.

[3] Efendi, Empy dan Hartono Zhuang. e-Learning Konsep dan Aplikasi. Yogyakarta: Andi, 2005.

[4] Holzinger, A. ; Nischelwitzer, A. ; Meisenberger, M. Mobile Phones as a Challenge for M-Learning: Examples for Mobile Interactive Learning Objects (MILOs). PerCom 2005 Workshops, Vol. No. 307-311.

[5] Parson, David. A Design Requirment Framewrok Mobile Learning Environment. Journal of Computer, Vol. 2 No. 4
[6] Quinn, C. M-Learning, Mobile Wireless in Your Pocket Learning. Fall : LiNe Zine, 2000.

[7] Suhendar. A. Visual Modelling Menggunakan UML dan Rational Rose. Bandung : Informatika, 2002

[8] Tantra, Rudy. Manajemen Proyek Sistem Informasi. Yogyakarta : Andi, 2012.

[9] Wahono. Sistem eLearning Berbasis Model Motivasi Komunitas. Jurna Teknodik, Vol. XI No. 21. 60-80.

[10] Widhiartha, Putu Ashintiya. Lesson Study, Sebuah Upaya Peningkatan Mutu Pendidik, Pendidikan Non Formal. Surabaya: Prima Printing, 2008.

[11] Widjaya, Iwan Kurniawan. Manajemen Proyek Teknologi Informasi / GHI. Jakarta : Graha Ilmu, 2013. 